\title{
TCR Input to NUREG-1537 Process for Advanced Nuclear Technologies Derived from Additive Manufacturing
}

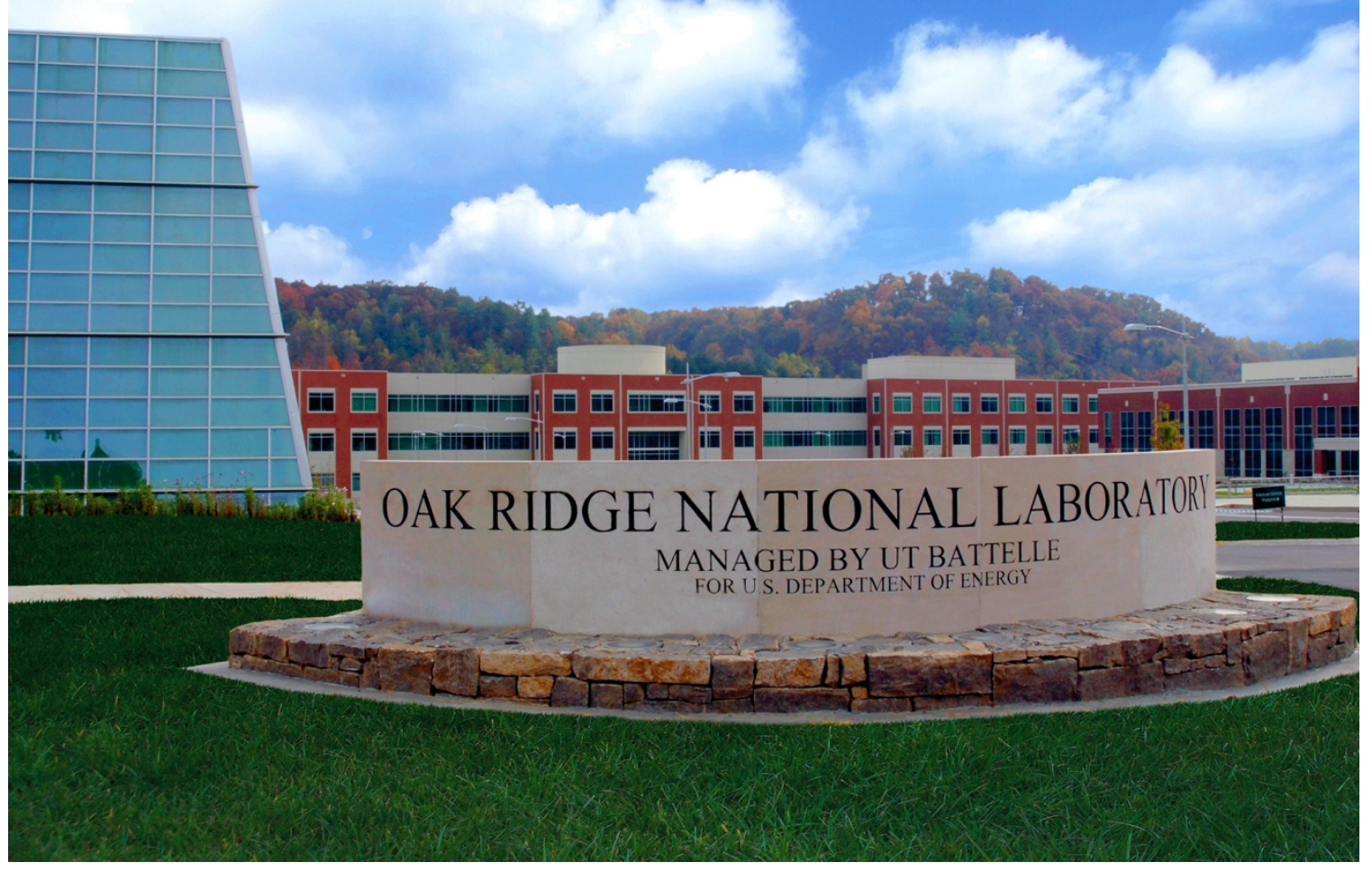
A. J. Huning
R. Fair
A. L. Coates
B. Lin

June 2021 


\section{DOCUMENT AVAILABILITY}

Reports produced after January 1, 1996, are generally available free via US Department of Energy (DOE) SciTech Connect.

Website www.osti.gov

Reports produced before January 1, 1996, may be purchased by members of the public from the following source:

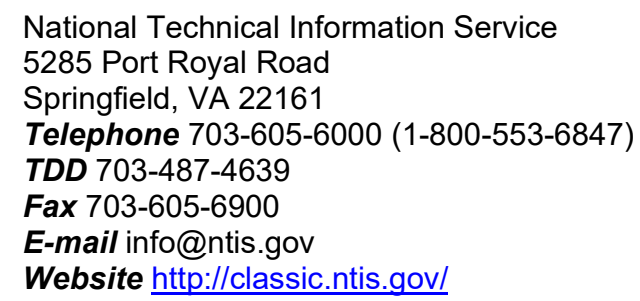

Reports are available to DOE employees, DOE contractors, Energy Technology Data Exchange representatives, and International Nuclear Information System representatives from the following source:

Office of Scientific and Technical Information

PO Box 62

Oak Ridge, TN 37831

Telephone 865-576-8401

Fax 865-576-5728

E-mail reports@osti.gov

Website https://www.osti.gov/

This report was prepared as an account of work sponsored by an agency of the United States Government. Neither the United States Government nor any agency thereof, nor any of their employees, makes any warranty, express or implied, or assumes any legal liability or responsibility for the accuracy, completeness, or usefulness of any information, apparatus, product, or process disclosed, or represents that its use would not infringe privately owned rights. Reference herein to any specific commercial product, process, or service by trade name, trademark, manufacturer, or otherwise, does not necessarily constitute or imply its endorsement, recommendation, or favoring by the United States Government or any agency thereof. The views and opinions of authors expressed herein do not necessarily state or reflect those of the United States Government or any agency thereof. 
Transformational Challenge Reactor

\title{
TCR INPUT TO NUREG-1537 PROCESS FOR ADVANCED NUCLEAR
} TECHNOLOGIES DERIVED FROM ADDITIVE MANUFACTURING

\author{
Alexander J. Huning \\ Randall Fair \\ Alyson L. Coates \\ Bruce Lin
}

June 2021

M3TC-21OR0405012

\section{Prepared by}

OAK RIDGE NATIONAL LABORATORY

Oak Ridge, TN 37831-6283

managed by

UT-BATTELLE, LLC

for the

US DEPARTMENT OF ENERGY

under contract DE-AC05-00OR22725 



\section{CONTENTS}

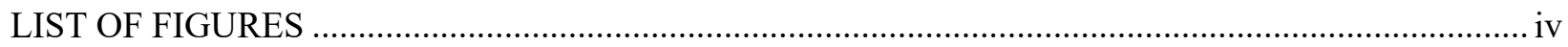

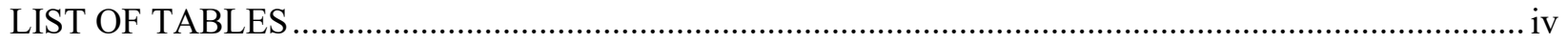

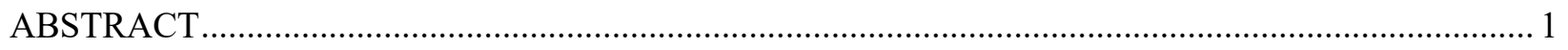

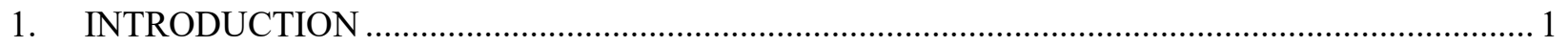

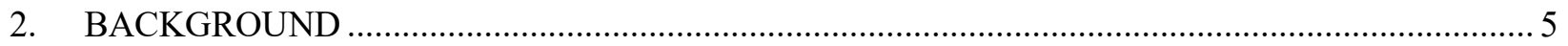

3. ASSESSMENT OF NUREG-1537 FOR AMT-DERIVED COMPONENTS _................................. 7

4. COMPONENT SAFETY CLASSIFICATION AND DOSE THRESHOLDS ............................. 8

5. ENGINEERING SAFETY FEATURES AND FUNDAMENTAL SAFETY FUNCTIONS............ 14

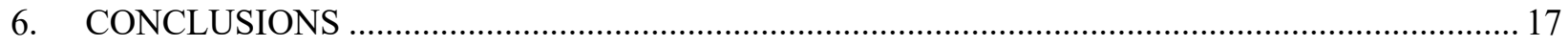

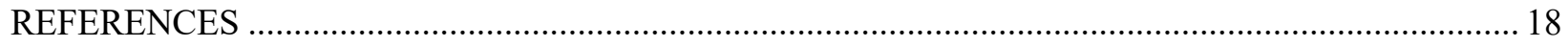

APPENDIX A. SUGGESTED MODIFICATIONS TO NUREG-1537 FOR ADVANCED NUCLEAR TECHNOLOGIES UTILIZING COMPONENTS DERIVED FROM ADDITIVE MANUFACTURING 


\section{LIST OF FIGURES}

Figure 1. TCR key research and development thrusts. .................................................................... 1

Figure 2. Safety analysis process as defined in DOE-STD-3009................................................... 9

Figure 3. Recommended Safety Analysis Process for low-hazard advanced reactors following

NUREG-1537.

Figure 4. TCR design feature relationship to fundamental safety functions with NUREG-1537 chapters.

Figure 5. TCR barriers and pathway for potential radionuclide release.

\section{LIST OF TABLES}

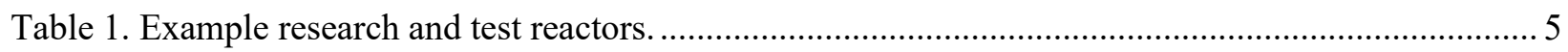

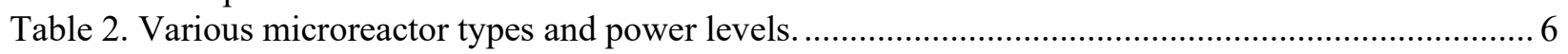

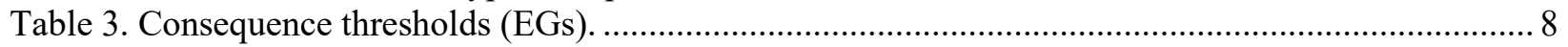

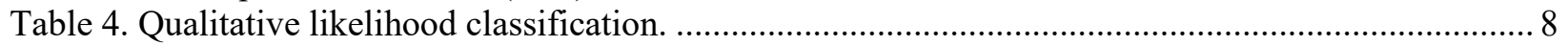

Table 5. NUREG-1537 Part 2, Dose threshold guidelines for reactors licensed after January 1, 1994. 


\section{ACRONYMS}

$\begin{array}{ll}\text { AM } & \text { additive manufacturing } \\ \text { AMT } & \text { advanced manufacturing technology } \\ \text { CFR } & \text { Code of Federal Regulations } \\ \text { DOE } & \text { US Department of Energy } \\ \text { DSA } & \text { Documented Safety Analysis } \\ \text { ECCS } & \text { emergency core cooling system } \\ \text { EG } & \text { evaluation guideline } \\ \text { ESF } & \text { engineered safety feature } \\ \text { FSF } & \text { fundamental safety function } \\ \text { ISG } & \text { Interim Staff Guidance } \\ \text { MHA } & \text { Maximum Hypothetical Accident } \\ \text { MOI } & \text { maximally exposed offsite individual } \\ \text { NRC } & \text { US Nuclear Regulatory Commission } \\ \text { ORNL } & \text { Oak Ridge National Laboratory } \\ \text { SHINE } & \text { SHINE Medical Technologies, LLC } \\ \text { TCR } & \text { Transformational Challenge Reactor } \\ \text { TRISO } & \text { tri-structural isotropic }\end{array}$




\begin{abstract}
There has been a renewed interest by several advanced reactor developers to use NUREG-1537 "Guidelines for Preparing and Reviewing Applications for the Licensing of Non-Power Reactors" as a basis for their safety analysis report content and organization. Recently, SHINE Medical Technologies, LLC (SHINE), which is a non-power, Aqueous Homogenous Reactor design radioisotope production facility, received a construction permit based around their NUREG-1537 safety evaluation report (ADAMS No. ML16229A140).

Advanced reactor developers are interested in using NUREG-1537 as a basis for their safety analysis report content and organization because of its successful application towards research reactors, graded approach, and simplicity in structure and requirements. However, NUREG-1537 is still largely geared toward light water reactors (LWRs) and many improvements could be made or supported through guidance documents for advanced reactors. For nuclear power to play a role in the future zero-carbon energy portfolio, a supportive regulatory structure is needed to lower regulatory uncertainty and barriers to deployment. At the time of this report, no such document or pathway exists for advanced nuclear technologies, including those derived from nontraditional technology such as advanced manufacturing technology (AMT) and, specifically, additive manufacturing. This report will explore and provide recommendations as to how advanced nuclear technologies derived from additive manufacturing technologies could employ the use of an ISG, other guidance document, or revisions to NUREG-1537 to lower the regulatory uncertainty and barriers for adoption.
\end{abstract}

\title{
1. INTRODUCTION
}

The Transformational Challenge Reactor (TCR) is being designed at Oak Ridge National Laboratory (ORNL) to demonstrate the feasibility of constructing a reactor core using advanced manufacturing technology (AMT). This technology includes additive manufacturing (AM) combined with machine learning, materials science, and data science technologies in an effort to facilitate the expansion of AM into advanced nuclear energy systems and other applications requiring a high level of quality assurance. The TCR is employing AM and artificial intelligence to deliver a new approach. Figure 1 illustrates the four key technical thrust areas for the TCR program.

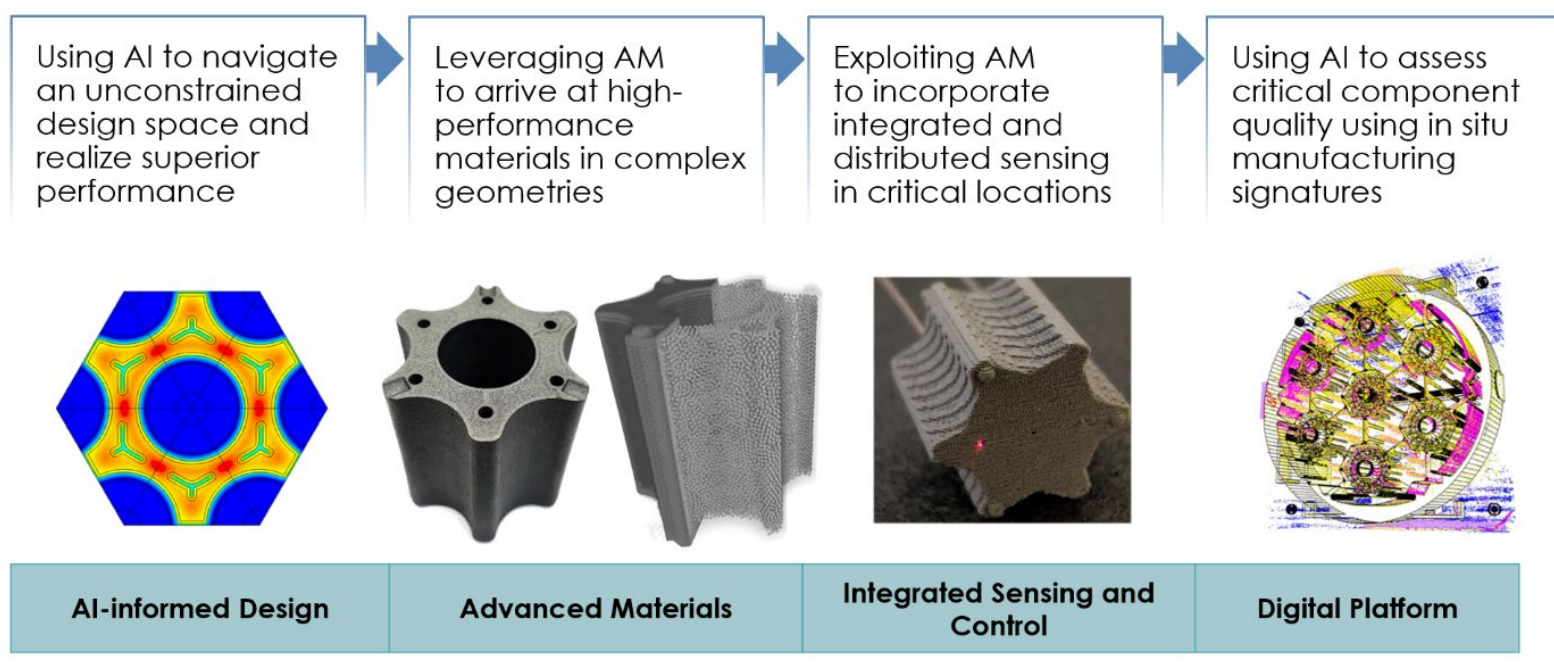

Figure 1. TCR key research and development thrusts. 
Operation of the TCR will result in considerable benefit within the nuclear community in demonstrating the use of advanced manufacturing to fabricate critical reactor components without negatively affecting public health or the environment. The major components of this effort include the following:

- Using high-fidelity modeling and simulation to assess performance of complex advanced manufactured geometries

- Developing and improving materials and fuels, including generating the thermophysical and mechanical data needed to assess performance under irradiation

- Employing various advanced manufacturing methods to fabricate components of intricate design to improve component and system performance

- Establishing a feasible path for component prototyping to integrate approaches that enable repeatability and qualification (e.g., sensors, quality assurance, fault detection software systems, and so on)

- Integrating instrumentation sensors into components during the fabrication process to provide realtime performance information.

The TCR is a helium-cooled, $3 \mathrm{MWt}$, high-temperature gas reactor. The reactor core incorporates conventionally manufactured tri-structural isotropic (TRISO) fuel particles of high-assay low enriched uranium in an advanced manufactured silicon carbide fuel element. Moderation is provided by solid yttrium hydride rods encapsulated in steel and interspersed throughout the core. The core is inside a reactor pressure vessel with axial reflectors composed of silicon carbide located inside the reactor vessel and a radial reflector composed of steel located outside of the vessel. The reactor is controlled with a control shroud composed of boron carbide that is located between the pressure vessel and the radial reflector [1].

The facility would be constructed in a remote area of ORNL on the former Health Physics Research Reactor site, which was decommissioned in the 1990s. Building the TCR on this site is the Proposed Action in an ongoing Environmental Assessment. This site was selected because of its remoteness from other ORNL facilities. The reactor would be operated for less than 24 effective full-power hours to minimize burnup and the radionuclide source term.

Inherent safety characteristics of the reactor include the following:

- Using low enriched uranium and limiting the moderator element size result in a negative temperature reactivity coefficient.

- Because the TCR is helium-cooled, reactivity is insensitive to coolant density changes.

- The fuel-to-moderator ratio is selected so that the core is under moderated, and no credible scenario exists that increases the hydrogen concentration within the solid hydrogenous moderator.

- Individual control shroud segments are worth little. No credible scenario exists in which to inject positive reactivity via the designed mechanism.

- The core is not large enough for xenon instabilities and is designed with very low excess reactivity. 
In 10 Code of Federal Regulations 830 (10 CFR 830), Nuclear Safety Management, Subpart B, Appendix A, Table 2 lists acceptable methodologies for developing a Documented Safety Analysis (DSA) for various types of nuclear facilities. Notably, the US Department of Energy (DOE) DSA is analogous with the US Nuclear Regulatory Commission (NRC) Safety Analysis Report. The acceptable methodology listed for a DOE reactor is NRC Regulatory Guide 1.70 [2], Standard Format and Content of Safety Analysis Reports for Nuclear Power Plants (LWR Edition), or a successor document. This Regulatory Guide was developed for large commercial light-water power reactors. The difference between the TCR and commercial reactors in power output, radiological source term, fuel type and composition, and operational life span makes applying the Regulatory Guide to the TCR overly burdensome relative to the value added.

DOE-STD-1083-2009, Processing Exemptions to Nuclear Safety Rules and Approval of Alternative Methods for Documented Safety Analyses [3], Section 4.2, provides a structured procedure for requesting approval of an alternate methodology to develop a DSA other than the methodologies explicitly included in Table 2 of 10 CFR 830, Subpart B, Appendix A.

NUREG-1537, Guidelines for Preparing and Reviewing Applications for the Licensing of Non-Power Reactors [4] was chosen for the basis for the TCR DSA. NUREG-1537 omits some key elements that are required by DOE and included in the submittal to DOE. Additions to NUREG-1537 requirements include the following:

- DOE-STD-3009-2014 Preparation of Nonreactor Nuclear Facility Documented Safety Analysis [5] will be used to augment the TCR DSA content associated with nonreactor operations that are performed to evaluate worker protection and ensure that the requirements of 10 CFR 830.204(6) are met.

- Evaluation guidelines (EGs) and consequence thresholds for the TCR will be consistent with DOESTD-3009-2014. Selection and functional classification of safety controls will also be consistent with guidance for safety structures, systems, and components and Specific Administrative Controls provided in this standard. Detailed information is provided in Section 4.

Additionally, a qualitative (semiquantitative) approach for hazards analysis and accident analysis with radiological release will be implemented as allowed by DOE-STD-3009-2014.

The discussion above reflects the DOE process for establishing an alternative approach to developing a DSA, which is the equivalent of a Safety Analysis Report for NRC-licensed facilities. The approach for NRC-licensed facilities takes a different path as demonstrated by actions leading up to application to NRC for an operating license by SHINE Medical Technologies, LLC (SHINE) in 2019 [6]. The SHINE facility is a nonpower, aqueous, homogenous reactor design for the purposes of radioisotope production.

Before application submittal, based on discussions between the U.S. Nuclear Regulatory Commission (NRC) staff and SHINE, the NRC staff understood that the proposed irradiation units were not nuclear reactors as defined in $\S 50.2$ of Title 10 of the Code of Federal Regulations (10 CFR 50.2). To assist in the application review of this facility, the NRC issued an Interim Staff Guidance (ISG) document to augment NUREG-1537 [7]. The ISG was prepared for evolving technologies that were not fully developed and demonstrated at the time of the ISG publication. The ISG is essentially a chapter-bychapter markup of NUREG-1537, making the document more applicable to radioisotope production facilities. The ISG noted that the irradiation units proposed by SHINE, could be licensed as a production facility pursuant to 10 CFR 50. Based on the guidance provided in the ISG, on March 26, 2013, and May 31, 2013, SHINE submitted a two-part construction permit application for a production facility as defined 
in 10 CFR 50.2. This rule allows NRC staff to conduct an efficient and effective licensing review of the SHINE construction permit application and any subsequent operating license application.

At the time of this report, no such document (ISG) or pathway exists for advanced nuclear technologies, including those derived from nontraditional technology such as AM. This report explores and provides recommendations as to how advanced nuclear technologies derived from AM technologies could employ the use of an ISG or revisions to NUREG-1537 to lower the regulatory uncertainty and barriers for adoption. Additionally, this report also contains recommendations for a few other chapters and sections in NUREG-1537, most notably Chapter 6 on Engineered Safety Features, which are based on observations from the development of safety basis documents for TCR. 


\section{BACKGROUND}

Significant advances in materials, computational, and manufacturing sciences have resulted in licensees investigating the use of parts and components fabricated by AMTs. In July 2020, the NRC published a white paper entitled, Advanced Manufacturing Technologies Application Guidance Framework [7]:

“...to provide a starting point for discussions with NRC stakeholders on potential guidance regarding the use of advanced manufacturing technologies (AMTs), which include those techniques and material processing methods that have not been traditionally used in the U.S. nuclear industry and have yet to be formally standardized by the nuclear industry (e.g., through nuclear codes and standards, through a submittal, or other processes resulting in NRC approval/endorsement)."

This framework is intended to be flexible, allowing a variety of both technical and regulatory approaches while ensuring that all important (i.e., safety-significant or safety-related) attributes of a specific AMT application that are unique to the use of AMT within that application are addressed. The two approaches discussed are an equivalency approach which demonstrates that the attributes of the AMT-derived components are sufficient to meet the original design and performance requirements for the part or component and an engineering design modification approach to demonstrate the adequacy of the AMT part or component.

The regulatory pathways discussed in the NRC framework are all related to the currently licensed facilities, such as the 50.59 process, submitting a license amendment, or requesting an alternate regulatory requirement. A pathway for using AM technologies in the licensing of a new facility is not addressed. A potential solution is the use of an ISG to NUREG-1537. The NRC has used an ISG to augment NUREG1537 in the past to assist the NRC staff in conducting efficient and effective licensing review of the SHINE construction permit application [8] and any subsequent operating license application. NUREG1537 is written specifically for light-water research and test reactors and has been used successfully for several reactor applications. A few examples are listed in Table 1.

Table 1. Example research and test reactors.

\begin{tabular}{|l|l|l|l|l|}
\hline \multicolumn{1}{|c|}{ Reactor } & \multicolumn{1}{c|}{ Design } & Power & \multicolumn{1}{c|}{ Purpose } & \multicolumn{1}{c|}{ Fuel } \\
\hline $\begin{array}{l}\text { National Institute of Standards and } \\
\text { Technology (NIST) Neutron-Beam Split } \\
\text { Core Rector (NBSR) }\end{array}$ & $\begin{array}{l}\text { High-flux, heavy-water- } \\
\text { moderated, cooled and } \\
\text { reflected test reactor }\end{array}$ & 20 MW & $\begin{array}{l}\text { Neutron-based } \\
\text { research }\end{array}$ & LEU \\
\hline $\begin{array}{l}\text { University of Missouri Research Reactor } \\
\text { (MURR) }\end{array}$ & $\begin{array}{l}\text { Pressurized, reflected, open- } \\
\text { pool-type, light-water } \\
\text { moderated and cooled, } \\
\text { heterogenous system }\end{array}$ & $10 \mathrm{MW}$ & $\begin{array}{l}\text { Research and } \\
\text { educational reactor }\end{array}$ & LEU \\
\hline $\begin{array}{l}\text { Massachusetts Institute of Technology } \\
\text { Reactor (MITR) }\end{array}$ & $\begin{array}{l}\text { Tank-type, light-water- } \\
\text { cooled and heavy-water- } \\
\text { moderated research reactor }\end{array}$ & $6 \mathrm{MW}$ & $\begin{array}{l}\text { Research and } \\
\text { educational reactor }\end{array}$ & HEU \\
\hline
\end{tabular}

There has been significant interest in the development and deployment of microreactors. Microreactors are small mobile nuclear reactors capable of producing about $1 \mathrm{MWt}$ to $20 \mathrm{MWt}$. In this report, these are also referred to as low-hazard advanced reactors because peak radionuclide inventory is roughly proportional to power level. However, it should not be assumed that low hazard equates to low risk or is inherently safer. Low-hazard designs are potentially safer because of their smaller radionuclide inventory, 
but they still require a satisfactory safety analysis that demonstrates their low risk to the public and workers.

It is envisioned that microreactors could be assembled in a factory using AMTs such as AM and shipped to a site. Table 2 lists some of the microreactor designs currently under development [9]. These reactors will be licensed within the bounds of NUREG-1537 and could benefit from this document if it is decided to use AM components either during the initial construction or for future replacement parts.

Table 2. Various microreactor types and power levels.

\begin{tabular}{|l|l|l|}
\hline \multicolumn{1}{|c|}{ Developer } & \multicolumn{1}{c|}{ Type } & \multicolumn{1}{c|}{ Power Levels } \\
\hline Oklo & Heat pipe FNR & $1.5 \mathrm{MWe}$ \\
\hline Westinghouse & Heat pipe FNR & $0.2-5 \mathrm{MWe}$ \\
\hline NuScale & Heat pipe & $1-10 \mathrm{MWe}$ \\
\hline UltraSafe Nuclear & HTGR & $5 \mathrm{MWe}$ \\
\hline HolosGen & HTGR & $3-13 \mathrm{MWe}$ \\
\hline X-energy & HTGR & $10 \mathrm{MWe}$ \\
\hline
\end{tabular}

FNR-Fast neutron reactor

HTGR - High-temperature gas-cooled reactor

As stated previously, several advanced reactor developers are interested in using NUREG-1537 as a basis for their safety analysis report content and organization. For these developers to be successful, a supportive regulatory structure is needed to lower regulatory uncertainty and barriers to deployment. The authors recommend that NUREG-1537 be revised or an ISG issued to facilitate licensing of advanced reactors that use components derived from advanced manufacturing processes. This report provides recommendations to providing a sound regulatory pathway for licensing and to greatly reduce the cost and risk undertaken by many advanced reactor developers. 


\section{ASSESSMENT OF NUREG-1537 FOR AMT-DERIVED COMPONENTS}

Appendix A to this document provides suggested changes to NUREG-1537 to accommodate use of AMT for parts and components. The appendix was produced to offer suggestions for developing an ISG document patterned after the ISG used for the SHINE facility, as discussed previously [6]. Paragraphs that contain suggested changes are presented.

In addition to the appendix, the next two chapters contain more focused recommendations developed from TCR regulatory observations and authorization interactions with the DOE. 


\section{COMPONENT SAFETY CLASSIFICATION AND DOSE THRESHOLDS}

Several chapters of NUREG-1537 reference ANSI/ANS-15.7, Research Reactor Site Evaluation, in defining radiological doses to the public and onsite personnel associated with the operation of research reactors licensed by the NRC. However, this standard has been withdrawn and does not contain the following critical elements:

- Dose consequence thresholds

- Methodology for selecting safety controls.

Because the TCR is a DOE research reactor, DOE-STD-3009 will be used for the TCR in providing both the consequence thresholds and safety classification methodology. The dose consequence thresholds are provided in Table 3.

Table 3. Consequence thresholds (EGs).

\begin{tabular}{|c|c|c|c|}
\hline $\begin{array}{c}\text { Consequence } \\
\text { level }\end{array}$ & Public $^{\mathbf{1 , 4}}$ & Colocated worker $^{\mathbf{2 , 4}}$ & $\begin{array}{c}\text { Facility } \\
\text { worker }^{\mathbf{3}}\end{array}$ \\
\hline High & $\begin{array}{c}\geq 25 \mathrm{rem} \text { Total } \\
\text { Effective Dose } \\
\text { (TED) }\end{array}$ & $\geq 100 \mathrm{rem}$ TED & $\begin{array}{c}\text { Prompt death, serious injury, or } \\
\text { significant radiological exposure }\end{array}$ \\
\hline Moderate & $\geq 5$ rem TED & $\geq 25 \mathrm{rem}$ TED & No distinguishable threshold \\
\hline Low & $<5$ rem TED & $\leq 25 \mathrm{rem}$ TED & No distinguishable threshold \\
\hline
\end{tabular}

${ }^{1}$ Maximally exposed offsite individual (MOI): A hypothetical individual defined to allow dose or dosage comparison with numerical criteria for the public. This individual is an adult typically located at the point of maximum exposure on the DOE site boundary nearest to the facility in question (ground-level release), or he or she may be located at some farther distance where an elevated or buoyant radioactive plume is expected to cause the highest exposure (airborne release); see Section 3.2.4.2 of DOE-STD-3009. The MOI used here is not the same as the Maximally Exposed Individual or the Representative Person used in DOE Order 458.1 for demonstrating compliance with DOE public dose limits and constraints.

${ }^{2} \mathrm{~A}$ colocated worker at a distance of $100 \mathrm{~m}$ from a facility (building perimeter) or estimated release point.

${ }^{3}$ A worker within the facility boundary and located less than $100 \mathrm{~m}$ from the release point.

${ }^{4}$ Although quantitative thresholds are provided for the MOI and colocated worker consequences, the consequences may be estimated using qualitative and/or semiquantitative techniques.

The hazard scenario likelihood is estimated consistent with the classification bins in Table 4 (also from DOE-STD-3009).

Table 4. Qualitative likelihood classification.

\begin{tabular}{|c|c|l|}
\hline Description & Likelihood range (/year) & \multicolumn{1}{|c|}{ Definition } \\
\hline Anticipated & Likelihood $>10^{-2}$ & $\begin{array}{l}\text { Events that may occur several times during } \\
\text { the lifetime of the facility (incidents that } \\
\text { commonly occur) }\end{array}$ \\
\hline Unlikely & $10^{-2}>$ likelihood $>10^{-4}$ & $\begin{array}{l}\text { Events that are not anticipated to occur during } \\
\text { the lifetime of the facility }\end{array}$ \\
\hline Extremely Unlikely & $10^{-4}>$ likelihood $>10^{-6}$ & $\begin{array}{l}\text { Events that will probably not occur during the } \\
\text { lifetime of the facility }\end{array}$ \\
\hline $\begin{array}{c}\text { Beyond Extremely } \\
\text { Unlikely }\end{array}$ & likelihood $<10^{-6}$ & All other accidents \\
\hline
\end{tabular}


In the case of the TCR, there will be no Facility Workers - no personnel will be closer to the facility than the control room (approximately $310 \mathrm{~m}$ ) during operation or while a radiological hazard exists inside the facility. Colocated workers are redefined as $310 \mathrm{~m}$ from the facility instead of $100 \mathrm{~m}$ to reflect actual conditions, and this redefinition will be justified in the facility's safety documentation approved by DOE.

The standard requires an unmitigated analysis of the consequences and likelihood of accidents. This analysis is required for plausible accident scenarios, Natural Phenomena Hazard events, and external events. The analysis provides a conservative estimate of the consequences to the facility worker, colocated worker, and MOI under the assumption that mitigative controls do not perform their safety functions. This estimate may be done either qualitatively in the hazard evaluation or quantitatively (for Design Basis Accidents/Evaluation Baseline Accidents) using the methodology prescribed in the standard.

The concept of an evaluation guideline (EG) was developed to help determine the rigor of controls needed to avoid the potential dose from an accident, to provide guidance in determining the level of planning necessary to respond to given accidents, or the training needed for individuals who may be placed in situations in which such doses might occur. To put the EG dose in perspective, the dose is based on a 50 year dose commitment that is 5 times the annual occupational limit for normal operations but equal to the federal guideline for allowable dose for emergency response workers in the case of lifesaving.

The EGs are a central element to the selection of safety controls. The basic process of selecting safety controls (i.e., safety classification of systems, structures, and components) is illustrated in Figure 2.

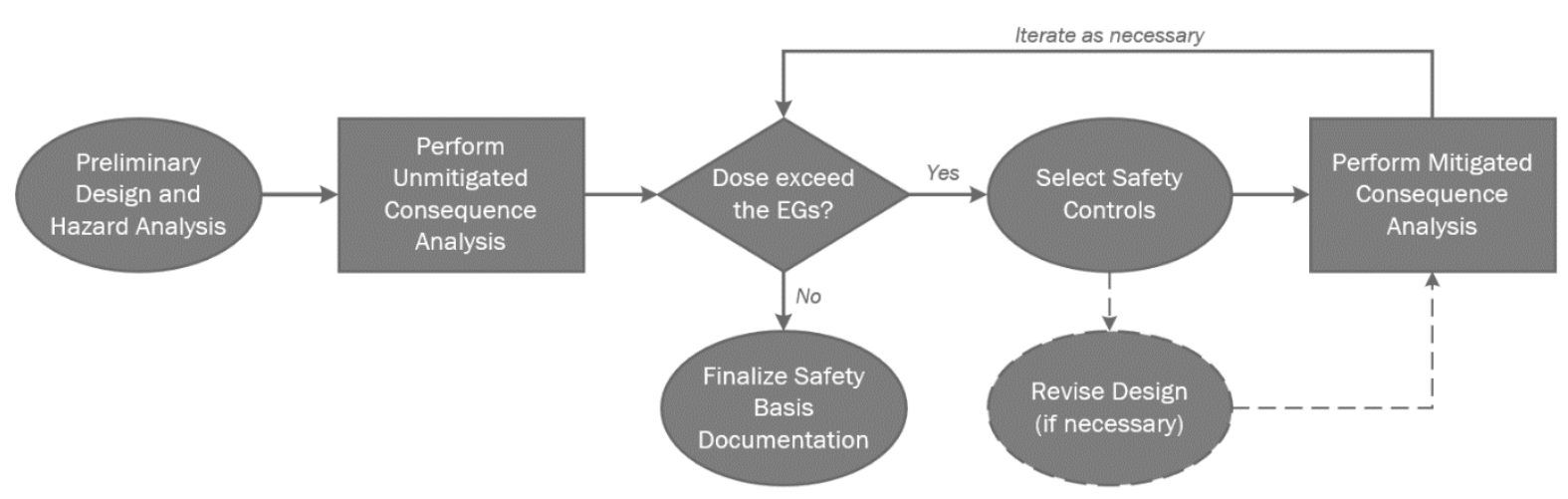

Figure 2. Safety analysis process as defined in DOE-STD-3009.

If the unmitigated release consequence for a design basis accident exceeds the EG for the public ( 25 rem; see Table 1), Safety Class controls are required to prevent the accident or mitigate the consequences to below the EG. If unmitigated offsite doses between $5 \mathrm{rem}$ and $25 \mathrm{rem}$ are calculated (i.e., challenging the EG), Safety Class controls should be considered, and the rationale should be described for decisions on whether or not to classify controls as Safety Class. If the unmitigated release consequence for a design basis accident exceeds the EG for the colocated workers (100 rem), Safety Significant controls are required. The difference between these two categories is quality and operational rigor requirements.

In the case of TCR, the offsite dose from a ground-level unmitigated release is approximately 4 rem. As shown in Table 3, a colocated worker is defined as a worker within $100 \mathrm{~m}$ from the source of radiation. The authors expect that $310 \mathrm{~m}$ (the distance from the control room to the confinement structure) will be approved to define a colocated worker because no personnel will be closer to the source during operation. If accepted, the worst-case credible accident results in an onsite ground-level unmitigated release of 43 rem, which would require no safety significant equipment to protect colocated workers [10]. 
In terms of NUREG-1537, the unmitigated consequence analysis is different from the Maximum Hypothetical Accident (MHA), which is described in Chapter 13, Accident Analysis.

\section{From NUREG-1537:}

"The MHA is the hypothetical accident in which the potential radiological consequences to the public health and safety are greater than those from any other postulated event at the facility. The MHA has the greatest radiological consequences of analyzed accidents for a non-power reactor to the facility staff, the public, and the environment The MHA is usually, but not always, associated with assumed fuel cladding or fission product retention failure and fission product release. This accident usually assumes conditions that are not considered credible, but are bounding and demonstrate that under the most extreme conditions and assumptions, the radiological consequences at a non-power reactor could not exceed previously used acceptance criteria (e.g., 10 CFR Part 20 or 100)."

And from DOE-STD-3009:

"An unmitigated consequence analysis shall be performed for plausible accident scenarios, NPH events, and external events. The hazard evaluation also presents the unmitigated dose consequence from a criticality accident as required by Section 3.1.3.2. The material quantity, form, location, dispersibility, and interaction with available energy sources are identified and documented. The intent is to provide a conservative estimate of the consequences to the facility worker, co-located worker, and MOI assuming that mitigative controls do not perform their safety functions."

Differences of the two approaches include the following:

- The unmitigated consequence analysis does not assume the function of any design feature that may mitigate the release beyond the initial assumptions of the radiological source (i.e., fuel type).

- The MHA assumes any or none of the design features may or may not be available to mitigate the release.

- The unmitigated consequence analysis is used as a precursor assessment to the selection of safety controls and to obtain a perspective of the residual risk associated with the operation of the facility.

- The analysis of the MHA is performed to adequately bound the uncertainty in the accident analysis and ensure that public safety limits are met.

- Both the unmitigated consequence and MHA are highly deterministic in their accident definition. However, the unmitigated consequence is not considered as a beyond design basis accident like the MHA. The unmitigated accident is considered as a design basis (i.e., "plausible") accident, before the introduction of safety controls.

- Neither the unmitigated consequence analysis nor the MHA are defined to be realistic or physically possible once safety design and mitigative features are considered. However, only the MHA is retained as the worst-case beyond design basis accident.

When comparing the two accidents, the MHA and the unmitigated consequence analysis, it is apparent from NUREG-1537 that the MHA should have the greater consequence to provide a bounding value. This presents some challenges since because the unmitigated accident is also assumed to have no mitigative 
features available beyond the initial assumptions. The question then arises: How can an unmitigated consequence analysis have a lower consequence than the MHA?

In the case of the TCR, and other potential DOE reactors following NUREG-1537 for their preliminary documented safety analysis/DSA, the proposed solution to this is an adequate definition of each with their purposes clearly stated. For example, the unmitigated accident is intended to be a "physically meaningful accident scenario" and some initial assumptions, such as passive safety controls, may be considered as protected TCR design features. For the MHA, an "incredible" failure of these controls, for which their function is assumed successful as an initial condition in the unmitigated accident, may be considered to sufficiently bound the consequences.

A similar process is recommended for demonstrating how safety controls are selected for future lowhazard advanced reactors following NUREG-1537. Although documenting safety design and decisionmaking processes are generally not required for safety basis documents, this process is presented as one option for new nuclear developers and for regulators to consider. This is because it mirrors both approaches from a DOE-STD-3009 perspective and an advanced reactor, licensing modernization perspective that uses quantitative risk metrics [11] instead of the consequence-only oriented metrics as a measure for determining the adequacy of safety controls and barriers. The process is shown in Figure 3.

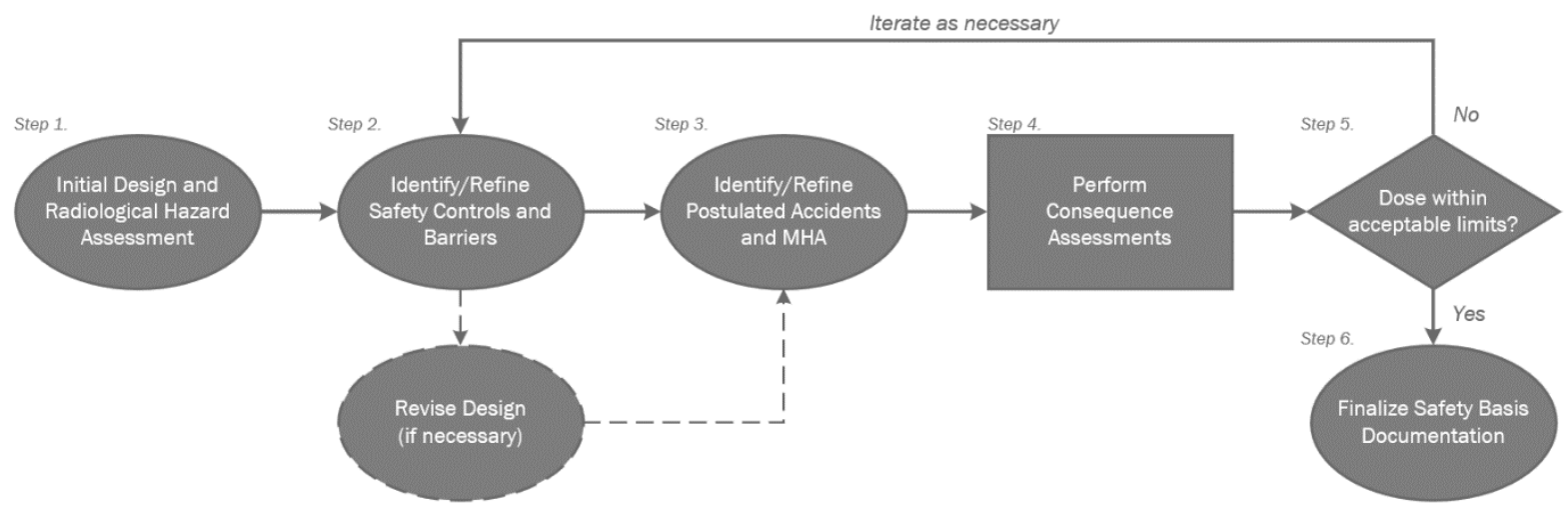

Figure 3. Recommended Safety Analysis Process for low-hazard advanced reactors following NUREG-1537.

In the recommended process, several differences from the DOE-STD-3009 process exist. First, the unmitigated consequence analysis is integrated with Step 1, Initial Design and Radiological Hazard Assessment. Because the purpose of the unmitigated consequence analysis is to initiate the process of identifying safety controls, the authors assumed for reactors that the unmitigated consequence would exceed low-dose threshold limits which would require some safety or mitigating controls. Although this may not be the case for all proposed nuclear facilities (e.g., very short operation, pulsed, and/or critical reactor systems), any research or demonstration reactor (e.g., $\geq$ hundreds of $\mathrm{kW}$ ) would be infeasible to operate with an entirely unmitigated consequence below all safety classification, dose-consequence thresholds. Therefore, the unmitigated consequence analysis is not presented in Figure 3 because the analysis is not a prerequisite to assessing if safety controls for a reactor are required or not. However, the unmitigated consequence analysis may be useful for characterizing the radiological hazard to gain a qualitative understanding of the expected barrier and safety control performances. Therefore, in Step 1, the Radiological Hazard Assessment is explicitly noted, and the authors assumed that an unmitigated consequence analysis or other technique would be used to gain this understanding.

Step 2, Identify/Refine Safety Controls and Barriers, comes before the consequence assessments and dose limit evaluation because it is assumed that some controls will be needed for a reactor, which is 
summarized in the description of Step 1. A high-level or conceptual understanding of these controls is necessary and is generally part of the initial design of a nuclear reactor.

Step 3, Identify/Refine Postulated Accidents and MHA, is generally understood as part of the mitigated consequence analyses step in Figure 1. This step is explicitly called out from the second part, consequence assessments, because the identification of accident scenarios can be complex and is inherently tied to the design and selected safety controls. Step 4, Consequence Assessments, is also included as part of the mitigated and unmitigated consequence analyses from Figure 1. No modifications are proposed for this step because it refers to the calculation of releases, radionuclide dispersion and atmospheric transport and total- or whole-body dose consequence calculations that are standard to any regulatory process. Additionally, this step may require thermal-hydraulic, neutronic, and other resources to adequately model and predict accident consequences.

For Step 5 (Dose within acceptable limits?), the limits would either be the DOE EGs (assuming it is a DOE reactor), as specified in DOE-STD-3009, or those stated in NUREG-1537 Part 2. These limits are summarized in Table 5 for NRC-licensed research and test reactors (i.e., nonpower).

Table 5. NUREG-1537 Part 2, Dose threshold guidelines for reactors licensed after January 1, 1994.

\begin{tabular}{|c|c|c|}
\hline Criterion & Dose threshold & Reference \\
\hline Research reactor $^{1}$ & $\begin{array}{c}\leq 5 \text { rem TED (occupational annual limit) } \\
\leq 0.1 \text { rem TED (public annual limit) }\end{array}$ & 10 CFR 20 \\
\hline Test reactor $^{2}$ & $\leq 25$ rem TED (public, low population zone) & 10 CFR 100 \\
\hline
\end{tabular}

${ }^{1}$ MHAs may have acceptable consequences that exceed these values, but these will be evaluated on a case-by-case basis.

${ }^{2}$ Values in 10 CFR 100 do not imply acceptable limits for emergency doses to the public under accident conditions. Rather, these values are to be used to evaluate reactor sites with respect to potential reactor accidents of exceedingly low probability of occurrence and low risk of exposure of the public to radiation.

For power reactors licensed by the NRC, dose thresholds for postulated accidents are found in $10 \mathrm{CFR}$ $\S 50.34(\mathrm{a})(1)(\mathrm{iii})(\mathrm{D})$ :

"The safety features that are to be engineered into the facility and those barriers that must be breached as a result of an accident before a release of radioactive material to the environment can occur. Special attention must be directed to plant design features intended to mitigate the radiological consequences of accidents. In performing this assessment, an applicant shall assume a fission product release ${ }^{6}$ from the core into the containment assuming that the facility is operated at the ultimate power level contemplated. The applicant shall perform an evaluation and analysis of the postulated fission product release, using the expected demonstrable containment leak rate and any fission product cleanup systems intended to mitigate the consequences of the accidents, together with applicable site characteristics, including site meteorology, to evaluate the offsite radiological consequences. Site characteristics must comply with part 100 of this chapter. The evaluation must determine that:

(1) An individual located at any point on the boundary of the exclusion area for any 2 hour period following the onset of the postulated fission product release, would not receive a radiation dose in excess of 25 rem total effective dose equivalent (TEDE). 
(2) An individual located at any point on the outer boundary of the low population zone, who is exposed to the radioactive cloud resulting from the postulated fission product release (during the entire period of its passage) would not receive a radiation dose in excess of 25 rem total effective dose equivalent (TEDE);"

NUREG-1537 contains limited discussion of safety classification as related to the dose thresholds like DOE-STD-3009 does. The authors recommended that at an early stage, potential reactor developers following NUREG-1537 develop or specify their process for defining their hierarchy of safety controls. For the TCR, the DOE dose thresholds and process for selecting safety controls as specified in DOESTD-3009 are followed.

Finally, Step 6, Finalize Safety Basis Documentation, generally refers to the preliminary safety analysis report or preliminary documented safety analysis. Once the final safety analysis report or DSA is developed, the selection of safety controls and consequence assessments should confirm the selections in the preliminary safety analysis report/preliminary documented safety analysis without significant design revisions. Additionally, this includes the development of technical safety requirements based on the selected safety controls and their required performances to meet respective dose thresholds. 


\section{ENGINEERING SAFETY FEATURES AND FUNDAMENTAL SAFETY FUNCTIONS}

Chapter 6 of NUREG-1537 defines engineered safety features (ESFs) as:

"ESFs are active or passive features designed to mitigate the consequences of accidents and to keep radiological exposures to the public, the facility staff, and the environment within acceptable values. The concept of ESFs evolved from the defense-in-depth philosophy of multiple layers of design features to prevent or mitigate the release of radioactive materials to the environment during accident conditions."

The safety design can broadly be defined as the collection of physical, operational, programmatic, environmental, and other features which contribute to the fulfillment of the three fundamental safety functions (FSFs):

- Limiting the release of radioactive materials

- Controlling reactivity

- Removing heat from the reactor and waste stores

Failure to satisfy any of the three FSFs may result in an unacceptable consequence. Currently, safety functions are described along with the design criteria in Chapter 3 of NUREG-1537. The relationship between design features and FSFs, with TCR-specific examples, is shown in Figure 4.

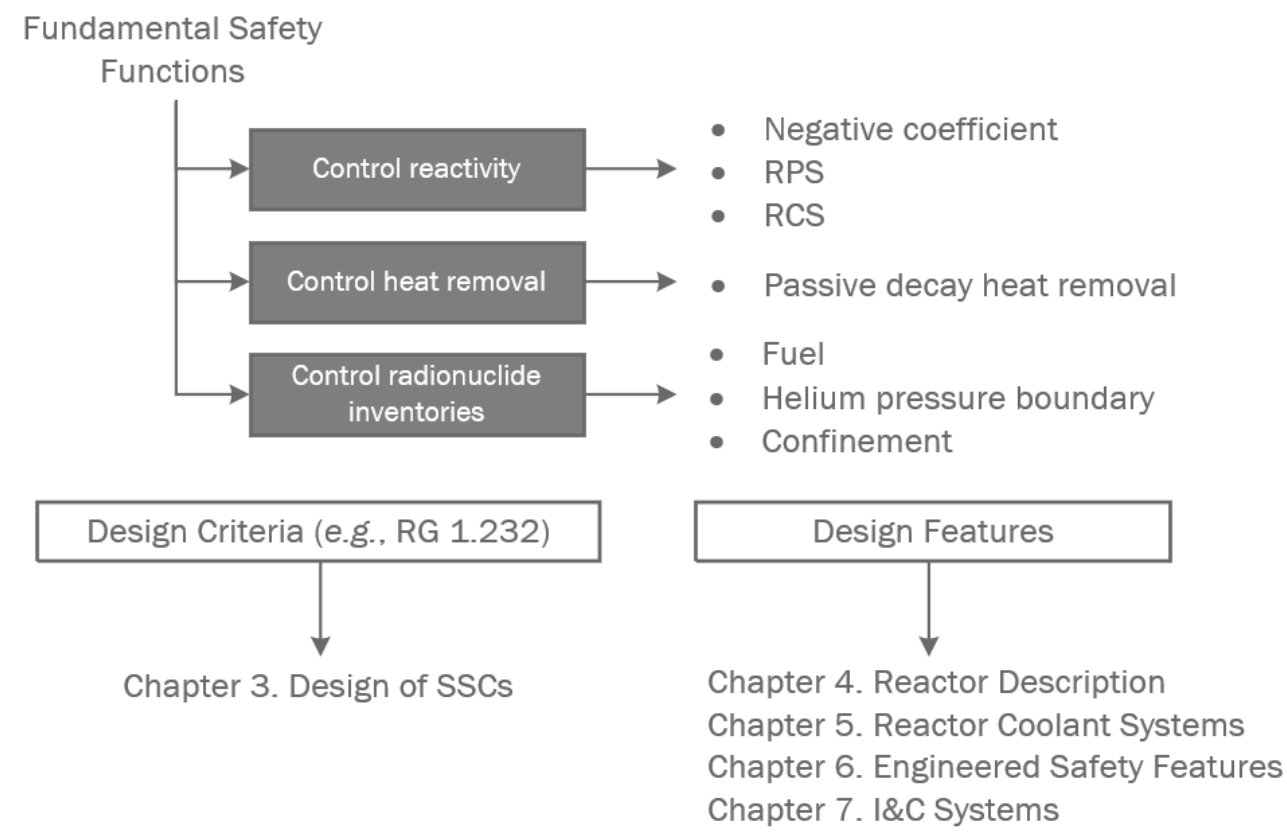

Figure 4. TCR design feature relationship to fundamental safety functions with NUREG-1537 chapters.

For the TCR, reactivity is controlled passively by providing a nuclear design that ensures a negative temperature reactivity coefficient and an under moderated core. Additionally, control shrouds are designed to preclude any credible scenario in which positive reactivity could be injected. Reactivity is controlled actively by a gravity-inserted shutdown rod and control shroud elements that do not penetrate a pressure boundary. 
Decay heat removal is accomplished by passive conduction and radiation to the confinement structure environment should all active heat removal capabilities be compromised. Active heat removal is via forced flow of helium through the reactor core coupled with a helium-to-air heat exchanger that discharges heat to the environment via a stack.

Chapter 6 of NUREG-1537 lists typical ESFs that may be required at nonpower reactors as (1) the confinement, (2) the containment, and (3) the emergency core cooling system (ECCS) and provides a detailed discussion of each. This recognizes that traditional barriers to the release of radioactive materials include the fuel itself, fuel cladding, the reactor coolant system boundary, and either a containment or confinement structure to limit the release of radionuclides during and after a release. The last line of defense should be a containment or confinement structure if the source term is great enough to warrant this protection.

However, because of advances in reactor fuel forms (e.g., TRISO fuel particles) capable of retaining radionuclides within the fuel itself, this chapter could be generalized in its discussion of a containment and confinement structures. Because the functional requirement is to limit the radiological dose, the concept of functional containment could be employed to facilitate nontraditional means of radionuclide retention. Recently, the NRC has recognized the importance of functional containment for non-light water reactors [12].

Figure 5 presents the key barriers and pathway for a potential radionuclide release for the TCR.

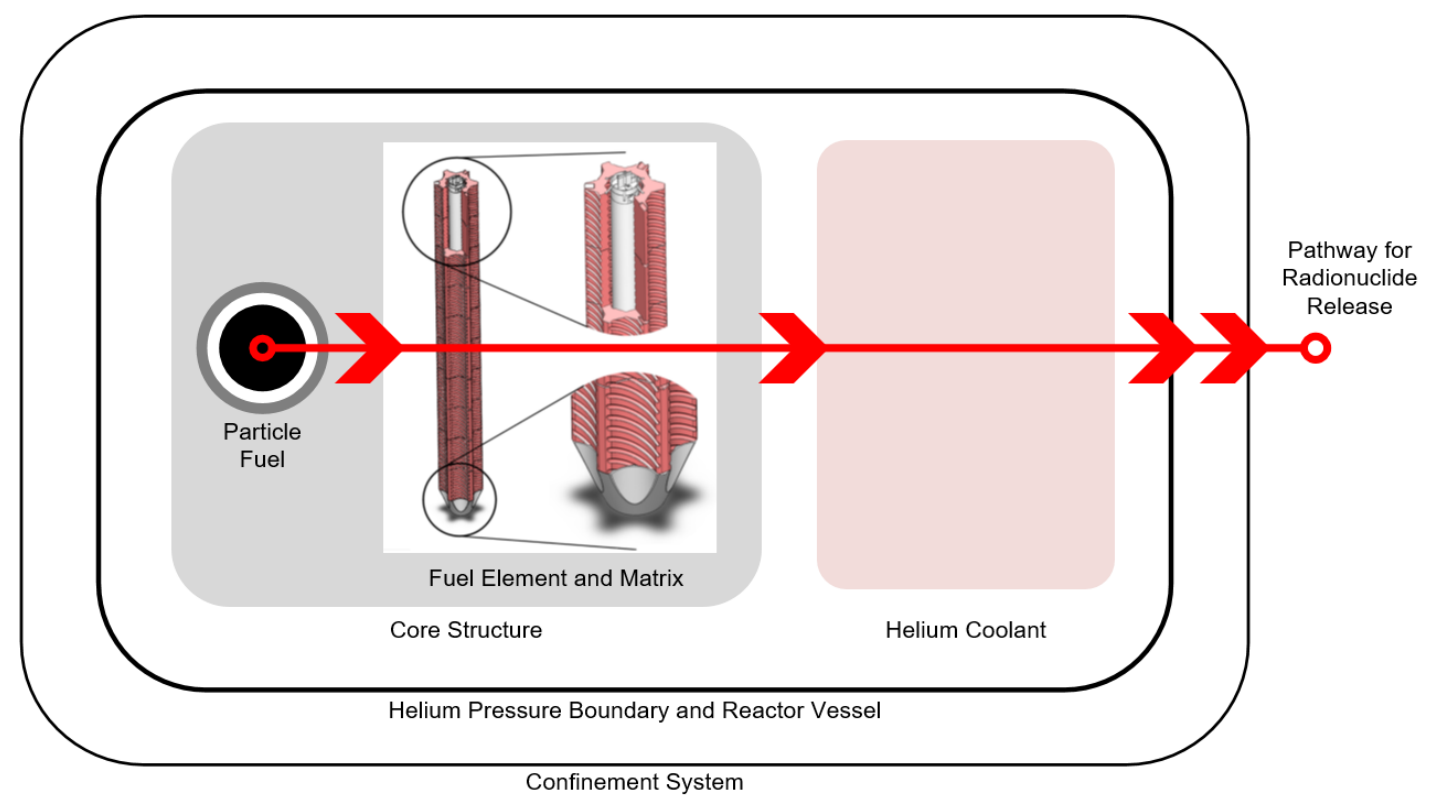

Figure 5. TCR barriers and pathway for potential radionuclide release.

As shown in Figure 5, the key barriers that can mitigate a potential radionuclide release include the

- coated particle fuel,

- ceramic matrix of fuel elements,

- reactor vessel and helium pressure boundary, and

- confinement system. 
Each barrier listed is expected to retain some quantity of radionuclides. In the event of a breach of the helium pressure boundary, this case is called a Depressurized Loss-of-Forced Circulation. The worst-case Depressurized Loss-of-Forced Circulation may assume no retention of radionuclides by the helium pressure boundary. However, the authors expect that the coated particle fuel and confinement system will retain a significant fraction of the radionuclides. The combined radionuclide retention performance represents the function of containment.

Much of the standard format and content description for Chapter 6 is applicable to the TCR and to any advanced reactor system considering a NUREG-1537 application. However, recommendations are made to the structure and organization of the chapter. These recommendations are based on the following observations:

- The role of ESFs is to mitigate the consequences of an accident and to keep radiological exposures within acceptable values.

- Failure to fulfill any FSF will result in an unacceptable consequence.

- Control of reactivity is essential, but it may be described in more detail in other sections of the safety basis documentation.

- ECCS is a light water reactor-specific system and is not appropriate for the TCR and other advanced reactor systems.

- Functional containment is more appropriate for many advanced reactor designs and is becoming an NRC-accepted concept, and it may include the traditional containment and confinement systems if they are employed.

Ultimately, the applicant and regulator must agree on the content and structure of the safety basis documentation. 


\section{CONCLUSIONS}

For advanced nuclear systems considering NUREG-1537 as their safety basis approach, several recommendations were presented based on insights gained from developing TCR preliminary safety basis documents and initial regulatory engagements. These recommendations can be encapsulated as:

- inclusion of a specific approach for safety classification with ties to dose consequence limits;

- modification of Chapter 6, Engineered Safety Features, with ties to fundamental safety functions and radionuclide retention; and,

- $\quad$ suggestions for developing an ISG or similar guidance document for advanced nuclear systems relying heavily on AMT-derived components, provided as an appendix.

Appendix A was developed as suggestions for developing an ISG or similar guidance document for use in licensing facilities incorporating AMT-derived components, similar to that developed for the SHINE facility [6].

The advent of diverse non-light water reactor test and research reactor systems accentuates the need for a more flexible approach to developing safety basis documents. This report is intended to address some of these issues. A detailed discussion of the use of AMT for fabricating reactor system components for TCR is being formalized in a report to be published at the end of the fiscal year. The authors recognize that because of the extremely small source term of the TCR, dose consequences are minimal, making the TCR an ideal testbed for incorporating new technologies (i.e., AMT). The ultimate goal beyond the TCR program is to be able to print quality components requiring a high degree of reliability and repeatability. This will be accomplished within the TCR program by creating meaningful correlations between in situ sensing data and fabrication of actual components employing artificial intelligence algorithms to ensure that the end product is qualified to perform its intended function.

A Preliminary Design Safety Analysis which includes detailed discussion and analysis of the use of AMT for the TCR has been drafted and will be completed pending sponsor approval and budget authority. The following statement is provided regarding the future of the TCR demonstration:

The TCR program's focus since its onset remains on elevating the readiness level of advanced technologies with a focus on additive manufacturing to enable optimal and cost-effective nuclear energy. The program strives to develop and demonstrate these technologies at high readiness level to facilitate widespread industrial and regulatory adoption. The specific nature of these demonstrations will be based on the guidance that we will receive from our managers at US DOE. For additional details please contact TCR Director, Ben Betzler. 


\section{REFERENCES}

[1] B. R. Betzler et al., "Transformational Challenge Reactor Preconceptual Core Design Studies," Nuclear Engineering and Design 367 (2020): 110781, https://doi.org/10.1016/j.nucengdes.2020.1107811.

[2] U S Nuclear Regulatory Commission, Standard Format and Content of Safety Analysis Reports for Nuclear Power Plants, Regulatory Guide 1.70, Washington, DC (1978).

[3] US Department of Energy Standard, Processing Exemptions to Nuclear Safety Rules and Approval of Alternative Methods for Documented Safety Analyses, DOE-STD-1083, Washington, DC (2015).

[4] US Nuclear Regulatory Commission, Guidelines for Preparing and Reviewing Applications for the Licensing of Non-Power Reactors," NUREG-1537, Washington, DC (1996).

[5] US Department of Energy, Preparation of Nonreactor Nuclear Facility Documented Safety Analysis, DOE-STD-3009-2014, Washington, DC (2014).

[6] SHINE Medical Technologies, LLC Application for an Operating License, ADAMS Accession Number: ML19211C143, July 17, 2019, https://www.nrc.gov/docs/ML1921/ML19211C044.pdf.

[7] US Nuclear Regulatory Commission, Advanced Manufacturing Technologies Application Guidance Framework, ADAMS Accession Number: ML20203M254, https://adamswebsearch2.nrc.gov/webSearch2/main.jsp?AccessionNumber=ML20203M254.

[8] US Nuclear Regulatory Commission, Guidelines for Preparing and Reviewing Applications for the Licensing of Non-Power Reactors, " Parts 1 and 2, for Licensing Radioisotope Production Facilities and Aqueous Homogeneous Reactors,; ADAMS Accession Number: ML12156A053, https://www.nrc.gov/docs/ML1215/ML12156A053.html.

[9] World Nuclear Association, "Small Nuclear Power Reactors,” (https://www.worldnuclear.org/information-library/nuclear-fuel-cycle/nuclear-power-reactors/small-nuclear-powerreactors.aspx).

[10] Fair, R., and A. Huning, TCR Postulated Accident and MHA Dose Assessment, ORNL/TM2021/1917, Oak Ridge, TN: Oak Ridge National Laboratory (2021).

[11] Nuclear Energy Institute, Modernization of Technical Requirements for Licensing of Advanced Non-Light Water Reactors: Risk-Informed Performance-Based Technology Inclusive Guidance for Non-Light Water Reactor Licensing Basis Development, NEI 18-01, Revision 1, ADAMS Accession Number: ML18094B085 (2019).

[12] US Nuclear Regulatory Commission, Functional Containment Performance Criteria for NonLight-Water-Reactors, SECY-18-0096, ADAMS Accession Number: ML18115A157 (2018). 
APPENDIX A. SUGGESTED MODIFICATIONS TO NUREG-1537 FOR ADVANCED NUCLEAR TECHNOLOGIES UTILIZING COMPONENTS DERIVED FROM ADDITIVE MANUFACTURING 



\section{APPENDIX A. SUGGESTED MODIFICATIONS TO NUREG-1537 FOR ADVANCED NUCLEAR TECHNOLOGIES UTILIZING COMPONENTS DERIVED FROM ADDITIVE MANUFACTURING}

Suggested additions to the text of NUREG-1537 are shown as underlined blue text.

\section{Chapter 1}

\subsection{INTRODUCTION}

The applicant should state its name and description (e.g., university, government agency, research institute, or company name) and should briefly state the purpose and intended use of the facility, the geographical location of the facility, the reactor type and power level, including principal inherent or passive safety features, and any unique design features including the use of advanced manufactured (AM) components. These topics should be covered in full and referenced to later chapters of the SAR.

The applicant should state safety criteria, the principal safety considerations, and the resulting conclusions, including brief discussions of the following:

\subsection{SUMMARY AND CONCLUSIONS ON PRINCIPAL SAFETY CONSIDERATIONS}

The applicant should state safety criteria, the principal safety considerations, and the resulting conclusions, including brief discussions of the following:

$\ldots$

- $\quad$ extent of use of AM components and the general effect on safety of operation and response of safety systems

\subsection{GENERAL DESCRIPTION OF THE FACILITY}

The applicant should briefly describe the reactor facility as follows: (1) geographical location; (2) principal characteristics of the site; (3) principal design criteria, operating characteristics, and safety systems; (4) any engineered safety features; (5) instrumentation, control, and electrical systems; (6) reactor coolant and other auxiliary systems; (7) radioactive waste management provisions (or system) and radiation protection; and (8) experimental facilities and capabilities. The general arrangement of major structures and equipment should be indicated with plan and elevation drawings. Safety features of the facility that are likely to be of special interest should be briefly identified. Such items as unusual site characteristics, the containment building, novel designs of the reactor, AM components, or unique experimental facilities should be highlighted. The information and discussions in this section in no way should substitute for the complete discussion and analysis found in (and referenced to) subsequent chapters of the SAR.

\section{Chapter 2}

No changes suggested

\section{Chapter 3}

[Introduction paragraph]

In this chapter of the SAR, the applicant should identify and describe the principal architectural and engineering design criteria for the structures, systems, and components that are required to ensure reactor facility safety and protection of the public. The material presented should 
emphasize the safety and protective functions and related design features that help provide defense in depth against uncontrolled release of radioactive material. The bases for the design criteria for some of the systems discussed in this chapter may be developed in 'other chapters and should be appropriately cross referenced. For example, confinement or containment design criteria may be summarized here and discussed in detail in Chapter 6, "Engineered Safety Features." Identify specific design criteria for fabrication and application of advanced manufactured parts and components.

\subsection{DESIGN CRITERIA}

In this section the applicant should specify the design criteria for the facility structures, systems, and components. The description of the actual design should be in the section or chapter that corresponds to the specific structure, system, or component. The design criteria should be both specific and general. The amount of detail given should be related to the safety function of the structure, system, or component. For example, general design criteria should include the following:

$\cdots$

- Design for AM parts and components. A graded approach may be employed based on the significance to safety of the part or component.

$\cdots$

To verify that seismic design functions are met, the applicant should give the bases for technical specifications necessary to ensure operability, testing, and inspection of associated systems, including instrumentation and control portions and components and parts which have been created by AM, if applicable.

\subsection{SYSTEMS AND COMPONENTS}

In this section the applicant should give the design bases for the systems and components required to function for safe reactor operation and shutdown. For non-power reactors, this section should include, at a minimum, the fuel system, control rod scram systems, other protective and safety systems; and the electromechanical systems and components associated with emergency core cooling systems, reactor room ventilation, confinement or containment systems, and other systems that may be required to prevent uncontrolled release of radioactive material, identifying components and parts of those systems which have been created by AM. The design criteria should include the conditions that are important for reliable operation of the systems and components (e.g., dynamic and static loads, number of cyclic loads, vibration, wear, friction, strength of materials, and effects of radiation and temperature). The specific application of these design criteria should generally be given in other chapters of the SAR. For example, if this chapter establishes that a design criterion for the control rods is that it drop by the force of gravity, Chapter 4, "Reactor Description," should describe the electromechanical and reactor dynamic design bases to accomplish this insertion within a specified time, normally 1 second.

$\underline{\text { Chapter } 4}$

\subsection{Summary Description}

The applicant should briefly address the following features of the reactor: 
$\cdots$

- application of Advanced Manufactured (AM) parts and components

\subsubsection{Reactor Fuel}

Most non-power reactors contain heterogeneous fuel elements consisting of rods, plates, or pins, which are addressed in the following sections. Homogeneous fuels and advanced fuel types (e.g., Tristructural Isotropic [TRISO]) should be described and analyzed in a comparable way. Information should be current; supported by referenced tests, measurements, and operating experience; and compared with additional applicant experience where applicable. The information should include the following:

$\ldots$

- Description of the basic fuel unit, including plates, rods, pins, pellets, and components and parts which have been created by AM, if any. This information should include dimensions, fabrication methods, and cladding or encapsulation methods. Special features, such as moderators or reflectors, external geometrical designs to enhance cooling capability, and inherent safety or feedback provisions should be discussed.

\subsubsection{Control Rods}

In this section the applicant should give information on the control rods, including all rods or control elements that are designed to change reactivity during reactor operation. The physical, kinetic, and electromechanical features demonstrating that the rods can fulfill their control and safety functions should be described. Results of computing control rod reactivity worth may be presented in this section, but details of the calculation of reactivity effects should appear in Section 4.5, "Nuclear Design," of the SAR. The information in this section should include the following:

$\cdots$

- Use of AM-manufactured parts and components, as applicable.

\subsubsection{Neutron Moderator and Reflector}

In this section the applicant should discuss the materials and systems designed to moderate the neutrons within the fuel region and reflect leakage neutrons back into the fuel region. The information should include the materials, geometries, designs for changes or replacement, provisions for cooling, radiation damage considerations, and provisions for experimental facilities or special uses. Multiple-use systems and features such as moderator coolant, fuel moderator, and reflector shield should be described. Use of AM parts and components should also be discussed. If moderators or reflectors are encapsulated to prevent contact with coolant, the effect of failure of the encapsulation should be analyzed. ...

\subsubsection{Neutron Startup Source}

In this section the applicant should present design information about the neutron startup source and its holder. The applicant should show that the source will produce the necessary neutrons to allow a monitored startup with the reactor instrumentation. The information should include the neutron strength and spectrum, source type and materials, its burnup and decay lifetime, and its regeneration characteristics. Other necessary information includes the material and geometry of the holder, use of AM parts and components, if any, the method of positioning the source in the core, and the core locations in which the source is designed to be used. . . . 


\subsection{Biological Shield}

In this section the applicant should present information about the principal biological shielding designed for the reactor. The information should include the following:

- The design bases for the radiation shields (e.g., water, concrete, or lead, AM parts and components), including the projected reactor power levels and related source terms and the criteria for determining the required protection factors 'for all applicable nuclear radiation activity. $\ldots$

- The materials used, including AM parts, and their shielding coefficients and factors, including a detailed list of constituents and their nuclear and shielding properties. The applicant should discuss radiation damage and heating or material dissociation during the projected lifetime of the reactor, induced radioactivity in structural components; potential radiation leakage or streaming at penetrations, interfaces, and other voids; shielding at experimental facilities; and shielding for facilities that store fuel and other radioactive materials within the reactor pool or tank.

\subsubsection{Normal Operating Conditions}

... Further information on power density limitations should be given in Sections 4.5.3 and 4.6. The information in the SAR should include the following:

- Use of AM parts and components, as applicable.

\section{Chapter 5}

\subsection{Primary Coolant System}

The basic requirements and design bases of the primary coolant system are to maintain reactor facility conditions within the range of design conditions and accident analyses assumptions derived from other chapters of the SAR, especially Chapters 4 and 13. The applicant should show the interrelationships among all SAR chapters and the way the designed primary coolant system provides all necessary functions. The following information should be included:

..

- Tables of allowable ranges of important design and operating parameters and specifications for the primary coolant system and its components, including:

- construction materials of components

- fabrication specifications of safety-related components

- $\quad$ use of AM parts or components

\subsection{Secondary Coolant System}

In this section the applicant should give information about those non-power reactors that include a secondary coolant system. For the others, the applicant should state that a secondary coolant system is not needed and should justify that conclusion. The following information should be provided: 
Tables of the range of important design and operating parameters and specifications of the secondary coolant system, including the following:

- Construction materials and fabrication specifications of components. (For older facilities for which complete information may not be available, the applicant should make a best effort to provide this information and should discuss the operating history of components.)

- Use of AM parts or components.

\section{Chapter 6}

[Introduction paragraph]

...The analyzed accident scenarios that the applicant should present in SAR Chapter 13 include the following:

- $\quad$ Include those events with failure of AM parts or components

- $\quad$ Include other important accidents identified specific to the design

Discussion of fundamental safety functions (FSFs), and which ESFs support which FSFs (include ECCS, Confinement, and Containment as appropriate). Definitions of ECCS, Confinement, and Containment can be replaced as appropriate with system references to the FSF.

\subsection{Summary Description}

No changes suggested.

\subsection{Detailed Descriptions}

System descriptions should be aligned with their role to fulfillment of FSFs.

\subsubsection{Control of Reactivity}

$\underline{\text { Summarize and reference other critical sections which describe the reactivity control and }}$ protection systems, as well as any passive means, such as negative temperature feedback.

\subsubsection{Control of Heat Removal}

No changes suggested from the ECCS section. Terminology should be changed to reflect the satisfaction of the FSF.

\subsubsection{Control of Radionuclides}

This section should emulate the NUREG-1537 descriptions for confinement and containment but include all barriers and systems that perform the function of containment. Appropriate radionuclide barrier release fractions should be justified with their impacts on potential consequences discussed.

\subsection{References}

No changes suggested. 
Chapters $7-12$

No suggested changes

Chapter 13

The information on credible postulated accidents should achieve the following objectives: ...

- Specifically call out events associated with failure of AM parts or components.

\subsubsection{Mishandling or Malfunction of Equipment}

This class of accident initiators represents failures or errors that do not fall into one of the other categories. Some initiators in this category are the following:

- $\quad$ Specifically call out events associated with failure of AM parts or components.

\subsection{Accident Analysis and Determination of Consequences}

In this section of the SAR, the applicant should discuss each event giving information consistently and systematically for gaining a clear understanding of the specific reactor and making comparisons with similar reactors. Many of the steps used to select the limiting event in each category may be semiquantitative. However, the analyses and determination of consequences of the limiting events should be as quantitative as possible and should include a discussion of any differences in consequences as a result of incorporating AM parts or components. 

